\title{
LER O PASSADO COM FERRAMENTAS DO FUTURO: UMA ANÁLISE DIGITAL DE TEXTOS CRÍTICOS DO INÍCIO DO SÉCULO XIX ${ }^{1}$
}

READING THE PAST WITH TOOLS OF THE FUTURE: A

DIGITAL ANALYSIS OF CRITICAL TEXTS FROM THE EARLY

NINETEENTH CENTURY

Marcia Abreu

Universidade de Campinas

Campinas - Brasil

Adiel Mittmann

Universidade Federal de Santa Catarina

Florianópolis - Brasil

\begin{abstract}
This article examines a set of critical texts produced in the United Kingdom, France and Portugal between 1797 and 1821 in order to understand how men of letters reacted to novels in the early nineteenth century and what criteria they used in their analyses. The paper inquires whether the language in which the texts were written and its purpose interfered in thinking about fiction. The study uses a digital annotation tool, DLNotes2, which allows comparisons between large amounts of data with an accuracy that a regular reading would not allow. The analysis revealed the existence of a transnational literate community, which thought about the novels in a very similar way.
\end{abstract}

Keywords: Literary criticism, digital humanities, novel, $19^{\text {th }}$ century.

\section{Résumé}

Cet article examine un ensemble de textes critiques produits au Royaume-Uni, en France et au Portugal entre 1797 et 1821 afin de comprendre comment les hommes de lettres ont réagi aux romans au début du XIXe siècle et quels critères ont-ils utilisés dans leurs analyses. On se demande si la langue dans laquelle les textes ont été écrits et son but a affecté la réflexion sur la fiction. L'étude

\section{Resumo}

Este artigo examinará um conjunto de textos críticos produzidos no Reino Unido, na França e em Portugal, entre 1797 e 1821, a fim de entender como os homens de letras reagiam aos romances no início do século XIX e que critérios empregavam em suas análises. Interessa também observar se a língua em que foram escritos os textos e a finalidade com que se produziram os comentários interferiram

1 Este trabalho foi realizado no interior do projeto "Circulação Transatlântica dos Impressos - a globalização da cultura no século XIX”, que contou com apoio da FAPESP e do CNPq. 
utilise un outil d'annotation numérique, DLNotes2, qui permet la réalisation des comparaisons entre de grandes quantités de données avec une précision qu'une lecture régulière ne permettrait pas. Les analyses ont révélé l'existence d'une communauté lettré transnationale, qui pensait sur les romans d'une manière très similaire.

Mots-clés: Critique littéraire, humanités numériques, roman, $19^{\mathrm{e}}$ siècle. no modo de pensar sobre a ficção. O estudo se vale de uma ferramenta digital de anotaçóes, denominada DLNotes2, que permite realizar comparaçóes entre grandes quantidades de dados com uma precisão que a simples leitura dos textos não permitiria. As análises revelaram a existência de uma comunidade letrada transnacional, que pensava sobre os romances de maneira bastante semelhante.

Palavras-chave: Crítica literária, humanidades digitais, romance, século XIX.

Apresentação do problema: a leitura erudita de romances no início do século XIX

Os romances eram considerados um gênero novo e pouco valorizado até o início do século XIX, pois não contavam com o reconhecimento das artes retóricas e poéticas, destinavam-se a públicos amplos e pouco instruídos, eram produzidos e comercializados em quantidades elevadas (ABREU, 2003).

Não obstante a rejeição ao gênero, ${ }^{2}$ a difusão mundial dos romances e sua ampla circulaçáo fez com que letrados de diversas nacionalidades manifestassem sua opinião sobre as obras, produzindo um conjunto de textos que permite observar como eles reagiam à prosa de ficção no início do século XIX e que elementos vinham às suas mentes quando tinham de avaliá-los. O fato de os textos críticos terem sido escritos por homens de letras e terem circulado em uma mesma época torna possível averiguar se havia consonâncias no modo de pensar e avaliar obras ficcionais, assim como analisar o impacto do local, da forma de divulgação dos textos críticos e da língua em que foram produzidos sobre o comentário, permitindo verificar qual a interferência desses elementos no modo de avaliar e pensar sobre a ficção.

Para pensar sobre essas questóes, examinaremos 150 textos críticos produzidos no Reino Unido, na França e em Portugal entre 1797 e 1821, empregando recursos computacionais que permitem a realização de comparaçóes acuradas entre eles.

2 Não há estabilidade na designação do gênero no século XVIII e início do XIX. Independentemente de sua extensão ou de características formais, a prosa de ficção era designada, em português, como novela, romance, conto; em inglês, como novel, story, romance, tale, short story, nouvelette, chronicle; em francês, como conte, nouvelle, nouvellette, roman. Há casos em que um único texto crítico utiliza dois ou mais destes termos para se referir a uma mesma publicaçấo. Neste artigo, utilizaremos apenas o termo romance para designar os textos em prosa ficcional. 
O extraordinário volume de romances em circulação no início do século XIX fez com que diversos periódicos dedicassem espaço à apreciaçấo dos livros saídos à luz, seja em língua nacional, seja em tradução, a fim de divulgá-los e de orientar o público em sua seleção de leituras. Propósitos semelhantes animaram a organização de livros que compendiavam e comentavam os romances tidos como mais relevantes ou mais aceitáveis. Em alguns países, como Portugal, a condução das escolhas dos leitores foi mais estrita, passando pelo crivo de organismos de censura, que produziam análises das narrativas a fim de liberar ou restringir sua circulação.

Considerando essas diversas motivaçóes para a produção de estudos críticos sobre romances, selecionamos 50 textos oriundos de periódicos britânicos, 50 vindos de bibliografias comentadas francesas e 50 provenientes de organismos de censura portugueses como corpus de análise para verificar semelhanças e diferenças no modo de examinar as narrativas ficcionais no início do século XIX.

As críticas publicadas em periódicos do Reino Unido foram recolhidas pelo projeto "British Fiction, 1800 - 1829: a Database of Production, Circulation, and Reception", desenvolvido no Centre for Editorial and Intertextual Research, da Cardiff University (Inglaterra). ${ }^{3}$ São textos críticos publicados nos periódicos La Belle Assemblée, Critical Review, Flowers of Literature e Monthly Review, que consideram as primeiras ediçóes de todas as obras ficcionais publicadas em inglês (como língua original ou como tradução), sem levar em conta reedições de romances publicados em data anterior a 1800.

Essas críticas, em linhas gerais, procuram informar sobre os lançamentos, avaliar o valor das obras e orientar os leitores na escolha do que ler na abundante oferta de livros. Tendo em vista as características da produção editorial britânica, a maior parte dos comentários diz respeito a obras originalmente escritas em inglês, já que as traduçôes não eram tão volumosas naquele momento. Na maioria dos casos, as críticas ocupavam um pequeno espaço nos jornais e não eram assinadas. De um total de 1007 críticas, foram selecionados aleatoriamente 50 textos, publicados entre 1800 e $1821 .^{4}$

3 A base reproduz anúncios de livros à venda publicados em periódicos, catálogos de bibliotecas e gabinetes de leitura, correspondência de escritores, listas de subscriçáo e textos críticos publicados na imprensa. GARSIDE, P. D.; BELANGER, J. E.; RAGAZ, S. A; MANDAL, A. A. British Fiction, 1800-1829: A Database of Production, Circulation \& Reception. Disponível em <http://www.british-fiction.cf.ac.uk>. Úlltimo acesso em 6 de março de 2017.

4 A seleção aleatória foi produzida por meio do website <https://www.random.org/lists $>$. Acesso em 11 de junho de 2015. 
Os comentários franceses são originados de duas publicações: Nouvelle Bibliothèque d'un Homme de Goût (1798) e Petite Bibliographie BiographicoRomancière ou Dictionnaire des Romanciers (1821).

O primeiro livro, como o próprio título indica, tinha por objetivo orientar os homens de "bom gosto" e, como informa o subtítulo, "apresentar um panorama da literatura antiga e moderna, no qual se dá a conhecer o espírito de todos os livros que apareceram em todos os gêneros até 1797, com um julgamento sumário e imparcial sobre cada obra, e a indicação das diferentes ediçóes que foram feitas, tanto na França como em países estrangeiros" (ANÔNIMO, 1798). A proposta foi bem acolhida entre os letrados, desde sua primeira aparição em 1772, fazendo com que o livro recebesse sucessivas ediçóes, em que se acrescentavam informaçóes sobre as novas obras saídas à luz, e eventualmente se alteravam alguns dos julgamentos. ${ }^{5} \mathrm{~A}$ fonte para algumas das avaliaçóes eram os textos críticos publicados em periódicos pelos "jornalistas mais conhecidos e [pelos] críticos mais estimados de nosso tempo" (ANÔNIMO, 1777). A seleção e organização das informaçôes estiveram a cargo dos "livreiros de Paris", referidos na segunda ediçấo, e em seguida de uma "sociedade de homens de letras", como informado na terceira edição.

Os comentários, em geral bastante sucintos, são organizados por temas ou por gêneros, e dispostos cronologicamente por nomes de autor. No caso dos romances, o livro apresenta, inicialmente, uma avaliação do gênero e um panorama de seu desenvolvimento histórico desde a Grécia, aos quais se seguem breves explanaçóes sobre o conjunto de romances compostos por determinado escritor. Apesar da promessa de exaustividade apresentada no subtítulo, a publicação traz um rol de obras que poderiam figurar em uma biblioteca selecionada.

A segunda obra francesa considerada, Petite Bibliographie BiographicoRomancière ou Dictionnaire des Romanciers, organizada pelo livreiro-editor Alexandre-Nicolas Pigoreau, também manifesta seus propósitos no título e subtítulo. O livro contém uma pequena bibliografia de romances, organizada em função do nome dos autores, considerando obras "tanto antigas quanto modernas, tanto nacionais quanto estrangeiras, com uma palavra sobre cada um deles e a notícia dos romances que eles compuseram, seja como autores, seja como tradutores". A página de rosto informa, ainda, que o dicionário é "precedido de um catálogo dos melhores romances publicados desde há muito e seguido de um panorama próprio a dar a conhecer os diferentes gêneros e a dirigir as escolhas das obras que devem formar a base de um gabinete de leitura”. (PIGOREAU, 1821)

5 Segundo "The history website of the Fondation Napoleon", a ideia original da compilação foi de Louis-Mayeul Chaudon. Disponível em <https://www.napoleon.org/en/history-of-the-two-empires/ biographies/barbier-antoine-alexandre/>. Acesso em 8 de março de 2017. 
Embora a dimensão biográfica seja destacada no título do livro, praticamente não há comentários sobre a vida dos escritores. Os curtos verbetes apresentam, abaixo do nome de cada romancista ou tradutor, uma breve avaliação e a lista dos romances que eles publicaram. Assim como ocorria com a Nouvelle Bibliothèque d'un Homme de Goût, o propósito da publicação era orientar a escolha do público, destacando-se, nesse caso, uma fatia particular: aqueles que mantinham ou queriam estabelecer um gabinete de leitura, atividade que o próprio Pigoreau desempenhava juntamente com as funçóes de editor-livreiro.

Assim como foi feito com as críticas britânicas, foram selecionadas aleatoriamente 25 avaliaçóes extraídas da Nouvelle Bibliothèque d'un homme de goût e 25 do Petite Bibliographie Biographico-Romancière, totalizando 50 textos.

A publicação de críticas sobre romance, em língua portuguesa, é praticamente nula no princípio do século XIX. A consulta à Hemeroteca Digital Brasileira, ${ }^{6}$ que reúne centenas de periódicos digitalizados com busca por OCR, identificou apenas dois textos críticos entre os 24 periódicos publicados entre o início da imprensa no Brasil (1808) e $1821 .^{7}$ A pesquisa realizada em periódicos lusitanos, tanto pela Hemeroteca Digital de Portugal, quanto por meio de busca em microfilmes, não obteve qualquer resultado. ${ }^{8}$ Entretanto, um grande volume de textos críticos foi produzido por censores a serviço do poder real entre 1768 (quando da instalação da Real Mesa Censória) até 1821 (suspensão da censura prévia). A função dos censores, estabelecida em alvarás régios, era apenas verificar a existência de desvios em relação à ortodoxia religiosa, política e moral, preparando textos que informassem ao tribunal censório sua opiniáo sobre estes elementos. Entretanto, os censores excediam grandemente a tarefa e teciam detalhadas consideraçóes sobre aspectos estéticos e composicionais dos romances que passavam por suas máos. ${ }^{9}$ Esses textos eram lidos no interior dos organismos de censura, que acatavam ou não suas sugestóes de supressão, aprovação ou reformulaçáo.

6 Disponível em <http://memoria.bn.br/hdb/periodico.aspx>. Acesso em 8 de março de 2017.

7 A busca foi feita por bolsistas do projeto Circulaçấo Transatlântica dos Impressos, por jornal e por período, com inserção de diversas palavras-chave como "romance", "novela", "conto". Foram realizadas também buscas pelos títulos dos principais romances do período. O primeiro texto crítico localizado foi "Atala, ou os amantes do dezerto". Correio Brasiliense ou Armazem Literario. Londres: W. Lewis, outubro de 1812. O segundo é uma nota de publicaçáo, sem título, relativa ao romance Marie ou les Hollandaises. Rio de Janeiro: Gazeta do Rio de Janeiro, 22 de outubro de 1814.

8 A Biblioteca Nacional Digital de Portugal pode ser acessada no endereço <http://purl.pt/index/geral/ PT/index.html $>$. A pesquisa em periódicos microfilmados conservados pela Biblioteca Nacional de Portugal, pelo Centro de História da Cultura (Universidade Nova de Lisboa) e pela Biblioteca Central da Faculdade de Ciências Sociais e Humanas (Universidade Nova de Lisboa) foi realizada por Beatriz Gabrielli, em pesquisa intitulado "Presença de Romances em Jornais Diários Portugueses entre 1808 e 1866”" (Processo FAPESP: 2013/23152-0).

9 Para uma discussão sobre a dimensão crítica dos pareceres de censura luso-brasileiros ver: ABREU, 2011. 
Entre 360 pareceres de censura sobre obras de Belas Letras (produzidos entre 1787 e 1821) conservados nos Arquivos Nacionais da Torre do Tombo (Lisboa - Portugal), selecionamos aleatoriamente 50 produzidos pelos dois censores que mais examinaram romances no período: Francisco Xavier de Oliveira e Johann Wilhelm Christian Müller (que assinava seus textos como João Guilherme Christiano Müller). Foram selecionados 12 textos de Oliveira e 38 de Müller, refletindo a quantidade desigual de pareceres que cada censor possui no total. Oliveira nasceu no Brasil, formou-se em Portugal, onde se tornou professor régio de Retórica e Poética. Publicou duas obras (OLIVEIRA, 1798; 1815) e deixou uma inédita (OLIVEIRA, s/d). Müller nasceu em Göttingen (Alemanha), onde cursou humanidades, línguas orientais e teologia. Mudou-se para Portugal, onde desenvolveu diversas atividades letradas, entre as quais a publicação de uma tradução intitulada Memoria sobre a Litteratura Portugueza, traduzida do inglez com notas illustradoras do texto, extraída de um ensaio preparado pelo historiador e poeta inglês Roberto Southey para a Quarterley Review de maio do mesmo ano (MULLER, 1809).

Assim, o corpus constituído é, ao mesmo tempo, diverso e semelhante. Diverso, pois alguns textos críticos têm autoria conhecida, outros ignorada; foram escritos em três línguas e em diferentes regiōes da Europa; tinham distintos propósitos; circularam de variadas maneiras; e foram publicados (quando o foram) sob várias formas. E são semelhantes por comentarem romances e por terem sido produzidos por homens de letras, em um mesmo período.

\section{Análise computacional dos dados: a ferramenta DLNotes2}

A leitura convencional de textos críticos permite perceber a ocorrência de determinados padróes e de modos comuns de comentar as obras ficcionais; permite também observar a existência de especificidades e peculiaridades nos textos. Salta aos olhos, por exemplo, que os comentários produzidos para a Nouvelle Bibliothèque d'un homme de gô̂t e os da Petite Bibliographie Biographico-Romancière são bastante sucintos e predominantemente elogiosos, enquanto os da censura lusitana e os da imprensa britânica variam de tamanho e apresentam opinióes diversificadas sobre a qualidade dos textos.

Entretanto, uma observação mais minuciosa e uma análise mais fina de um volume grande de textos se beneficiam do recurso a ferramentas digitais, pois elas permitem anotá-los e compará-los com um rigor que a simples leitura e a anotação manual têm dificuldades de atingir. 
Por isso, recorremos a uma ferramenta digital chamada DLNotes $2^{10}$, um software que permite ao pesquisador realizar anotaçóes em textos. Diferentemente do que se faz em anotaçóes tradicionais, o leitor não escreve livremente, mas deve selecionar elementos pré-estabelecidos e preencher atributos específicos. Desta forma, informaçôes estatísticas e comparaçôes acuradas podem ser extraídas do conjunto de anotaçôes feitas em um ou mais textos.

Para o estudo dos textos críticos oitocentistas, foi estabelecido um conjunto de critérios que acreditávamos poder ser empregado pelos letrados. ${ }^{11}$ Definimos alguns elementos de avaliação textual: enredo (quantidade de episódios, distribuiçáo e estruturação, tema e resumo), personagem (comentários sobre sua construção, sobre o fato de se tratar de um tipo ou um estereótipo, ou sobre a percepção de que se trataria de exemplo de vício ou de virtude), o narrador, a linguagem (do ponto de vista do estilo ou da correção ortográfica e gramatical), os diálogos, o humor (falta e presença), a ironia, as descriçôes (de paisagens, de ambientes), a verossimilhança (compreendida tanto como plausibilidade interna quanto como correspondência com a realidade, incluindo o comentário sobre o fato de o escritor ter ou não observado diretamente a realidade), a moral (tendo em vista o enredo, o comportamento de personagens, as reflexóes do narrador ou a linguagem), adequação (da fala, do nome ou da situação à condição da personagem; do tema ao gênero; e do ambiente à trama), e finalmente a qualidade da tradução. O comentário poderia ainda observar casos de plágio ou de imitação, ou pelo contrário destacar a originalidade da composição; e poderia deter-se sobre a questão da nacionalidade (anotaçóes sobre a contribuição do texto para a literatura nacional, com consequências sobre a linguagem ou sobre a caracterização da paisagem).

Determinamos, também, elementos extratextuais: a autoria (consideraçóes sobre o fato de a autoria ser masculina ou feminina, sobre a posição política do escritor, sua reputação, sobre seu interesse pecuniário e sobre o volume de sua produção), a imaginação do autor (notas sobre o excesso ou a falta de imaginação), a edição (comentários sobre a posição política do editor ou da casa editorial, sua reputação, seu interesse pecuniário,

10 Produzida pelo Núcleo de Pesquisas em Informática, Literatura e Linguística (NUPILL), e pelo Laboratório de Pesquisas em Sistemas Distribuídos (LAPESD), ambos da Universidade Federal de Santa Catarina. Cf. MITTMANN, 2013.

$11 \mathrm{O}$ estabelecimento dos elementos de análise e a produçấo das anotaçôes semânticas que validaram o sistema foram realizados por uma equipe coordenada por Márcia Abreu: Isabella Spatti Candido (bolsista Iniciação Científica FAPESP), Beatriz Gabrielli (bolsista Iniciaçāo Científica FAPESP e, atualmente, Mestranda com bolsa do CNPq), Larissa de Assumpção (bolsista de Iniciação Científica FAPESP e, atualmente, Mestranda com bolsa da mesma instituiçăo), Priscila Velloni (bolsista de Treinamento Técnico FAPESP), João Lucas Magalhães Moraes (bolsista SAE - UNICAMP), Taís Franciscon (Mestranda, CNPq), Etienne Sauthier (Pós-doutorado FAPESP). 
o volume de sua produçáo, além de comentários sobre o fato de o editor ser homem ou mulher), o público leitor (especulaçôes sobre o público atingido pela narrativa: amplo, feminino, infantil, juvenil, letrado, masculino), os efeitos de leitura provocados pelo texto (deleite, entretenimento, instrução, emoção, exemplos de conduta, seja sobre os hipotéticos leitores, seja sobre o próprio crítico), e a recepção do romance (considerando tanto a avaliação da crítica quanto o desempenho das vendas). Em algumas circunstâncias, eles davam informaçóes sobre dados bibliográficos e de materialidade, indicando o local de venda, o preço e discorrendo sobre a forma material do impresso (número de volumes, encadernação, qualidade do papel e da impressão). Sabíamos, também, que eles teciam consideraçóes sobre o gênero romanesco (discutindo questôes relativas à nomenclatura, aos subgêneros e à valoração do gênero) e comentavam não apenas a narrativa mas seu paratexto (notas, prefácio, posfácio, título).

Supúnhamos, também, que os críticos poderiam se valer de certos procedimentos discursivos ao elaborar seus textos, entre os quais o recurso às citaçôes e mençôes, copiando trechos do romance analisado, de outra obra ou de textos críticos e teóricos, além de mencionar nomes de romancistas e de estudiosos das letras, bem como fazer referências a outros gêneros. Ao elaborar suas análises, eles também poderiam recorrer à identificação, seja de modelos (romanescos e náo romanescos), seja da vida do autor da obra ou de escolas ou correntes literárias a que o texto pertenceria. Seria possível, também, que os críticos recorressem à ironia no comentário sobre o romance ou sobre seu autor. Observamos, também, que os críticos abordavam temas gerais ao escrever sobre os romances, tecendo consideraçôes sobre política, filosofia, história, religiáo, bem como discorrendo sobre sua vida pessoal e sobre sua atuação como crítico ou censor.

A Figura 1 mostra a tela de criação de anotaçôes na ferramenta DLNotes2: à esquerda estáo os elementos disponíveis para a anotaçáo de textos críticos, e à direita os códigos de identificação da obra criticada e da crítica, a partir dos quais se pode recuperar informaçóes sobre o autor, título, local e data de publicação. Além disso, é possível informar se o crítico opina sobre determinado elemento e, quando o faz, se sua opiniáo é positiva, negativa ou neutra. No caso da figura, a anotaçáo expressa que o crítico comenta acerca do interesse pecuniário presente na publicação da obra (no painel à esquerda) e que ele o vê como algo negativo (à direita, no atributo opiniáo do crítico). 
Figura 1. Tela de criação de anotação na ferramenta DLNotes2 .

\section{* Oeuvres de Madame de Villedieu (ID 1011/0014)}

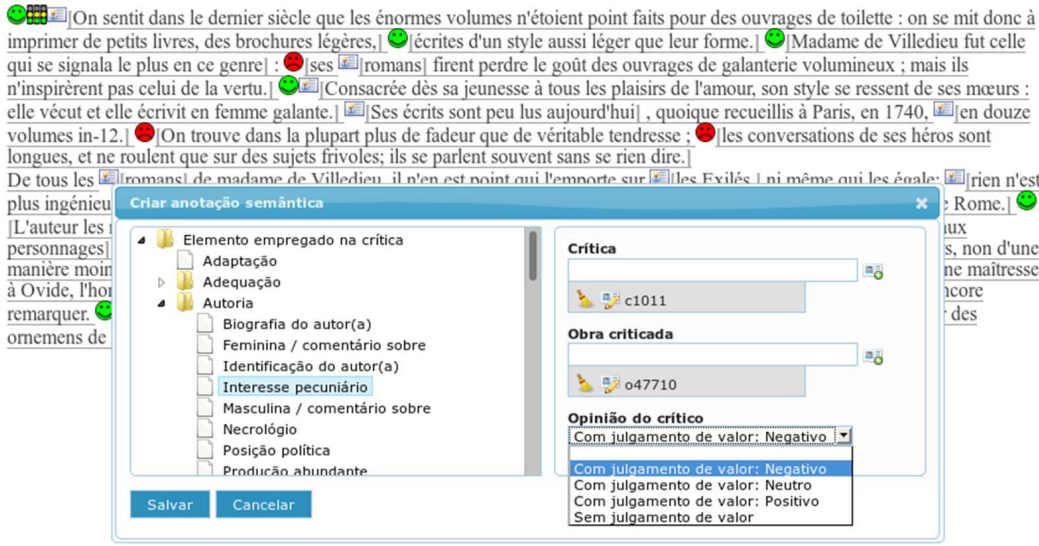

É possível combinar esses critérios para produzir anotações que correspondam aos vários aspectos abordados em determinado trecho, pois a ferramenta permite a inserção de mais de uma anotação por segmento por exemplo, um comentário sobre uma descrição da natureza tipicamente irlandesa relaciona-se não apenas com o quesito descrição, mas também com o item nacionalidade.

Concluída a análise do texto, ponderamos qual foi o resultado da crítica, verificando se a opiniấo do crítico sobre o romance foi negativa, positiva, predominantemente negativa, predominantemente positiva ou neutra.

As anotaçóes feitas com a ferramenta DLNotes2 podem ser exportadas em formato de banco de dados para serem analisadas em pacotes estatísticos, como se verá a seguir.

\section{Análise computacional de 150 textos críticos}

A partir do estabelecimento de 14 critérios de análise textual, 9 elementos extratextuais de avaliação e 5 procedimentos empregados na elaboração de textos críticos, imaginávamos que seria possível produzir anotaçóes extensivas e consistentes cobrindo os textos como um todo. ${ }^{12} \mathrm{~A}$ Tabela 1 exibe as principais estatísticas por origem dos textos: o número total de textos críticos, idêntico nos três casos; o número total de palavras em todos os textos; o tamanho médio, em palavras, dos textos; o número

12 Tendo em vista a instabilidade na designação do gênero no início do século, criamos também a possibilidade de anotar a terminologia empregada pelos críticos para se referir à narrativa. 
total dos elementos de análise encontrados; e o número médio de elementos encontrados nos textos.

Tabela 1. Sumário numérico dos textos anotados.

\begin{tabular}{lccccc}
\hline Origem & Textos & $\begin{array}{c}\text { Total de } \\
\text { Palavras }\end{array}$ & $\begin{array}{c}\text { Média de } \\
\text { Palavras por } \\
\text { Texto }\end{array}$ & $\begin{array}{c}\text { Total de } \\
\text { Elementos } \\
\text { Utilizados }\end{array}$ & $\begin{array}{c}\text { Média de } \\
\text { Elementos por } \\
\text { Texto }\end{array}$ \\
\hline Portugal & 50 & 29.930 & 598,6 & 26 & 8,3 \\
\hline França & 50 & 6.151 & 123,0 & 26 & 5,8 \\
\hline Reino Unido & 50 & 26.395 & 527,9 & 28 & 8,0 \\
\hline
\end{tabular}

Nossa primeira surpresa foi perceber que os críticos do início do século XIX operavam com um número reduzido de elementos. Praticamente não foram encontrados comentários sobre as descriçôes (exceto por 4 críticas inglesas) e os diálogos (1 censura em português e 4 críticas em inglês), humor (exceto por 7 críticas entre as 50 inglesas), ironia (empregada como recurso crítico, mas não como elemento de análise textual), narrador (2 textos em português e $2 \mathrm{em}$ inglês), originalidade ( 4 críticas em português, $1 \mathrm{em}$ francês e 13 em inglês), imitação ( 5 em português, 5 em francês e 2 em inglês) e adequação ( 6 em português, 1 em francês e 7 em inglês).

Tampouco houve preocupação com alguns elementos extratextuais como a imaginação (presente em 1 crítica em português, 6 em francês e 5 em inglês), a figura do editor (presente em apenas 3 textos portugueses, 3 franceses e 10 ingleses) e com os paratextos ( 7 em português e 8 em inglês). Da mesma forma, o procedimento crítico de identificação de modelos ou obras que poderiam ter sido uma referência na composição do romance examinado também não foi produtivo, já que apenas 2 textos portugueses, 1 francês e 3 ingleses recorreram a ele para a elaboração das análises.

Duas constataçôes interessantes podem ser extraídas desses dados. Em primeiro lugar, não há diferença significativa entre as línguas ou entre as finalidades da crítica no que tange à seleção dos critérios a serem empregados, tendo em vista a semelhança na pequena produtividade dos critérios acima, entre os quais se encontram alguns muito empregados atualmente, como o exame da figura do narrador ou a valorização da originalidade de uma narrativa. A identificação de escolas ou correntes literárias, hoje tão em voga, não produziu sequer um único comentário em qualquer das línguas, mostrando que a ideia de que as obras podem ser interpretadas em função de sua aderência a um estilo de época não fazia parte do repertório crítico no 
início dos oitocentos. Da mesma forma, a nacionalidade não foi um elemento muito produtivo, aparecendo nas críticas mais como designação de origem do que como elemento de composição e apreciação literária.

Em segundo lugar, observa-se que os críticos operavam com um número reduzido de elementos para pensar sobre os textos que liam. Excluindo-se as noções acima mencionadas, restam apenas 5 critérios textuais operacionais na produção das avaliaçôes críticas de romances: enredo, personagem, moral, verossimilhança e linguagem ao qual se podem somar observaçóes sobre a qualidade da tradução. Este número se torna ainda mais exíguo quando se percebe que alguns critérios eram muito mais produtivos do que outros.

O elemento mais empregado nos textos críticos foi o enredo, utilizado em 39 escritos ingleses (78,0\%), 36 portugueses $(72,0 \%)$ e 21 franceses $(42,0 \%)$, sobressaindo comentários sobre o tema e apresentação de resumos da narrativa - especialmente salientes nos textos britânicos. Esta é uma constatação surpreendente, principalmente no caso dos textos portugueses, que foram produzidos com a finalidade de avaliar a ortodoxia moral, política e religiosa dos romances, diante de um tribunal censório. Mesmo assim, os censores julgaram importante relatar a trama da narrativa para seus colegas, que decidiriam se o livro poderia ou não circular em Portugal e seus domínios. Entre os britânicos, cujas críticas eram publicadas na imprensa com vistas, sobretudo, a divulgar lançamentos, é mais compreensível o recurso à apresentação do enredo. Entretanto, não se prestava qualquer atenção ao que hoje chamamos de spoiler, já que as consideraçóes sobre o enredo, em geral, focavam-se na apresentação de um resumo da narrativa, relatando todos os pontos relevantes, inclusive o final da história - o que, talvez, indique que a curiosidade sobre o desfecho das narrativas seja tributária do desenvolvimento dos romances em folhetim.

$\mathrm{O}$ caso francês, em que numericamente recorre-se um pouco menos às consideraçôes sobre o enredo, é também impressionante, pois os textos inseridos nas duas bibliografias francesas são bastante sintéticos e são ocupados, sobretudo, por indicaçóes relativas aos dados bibliográficos (presentes em $66,0 \%$ dos textos), indicação do nome do autor $(76,0 \%)$ e menção ao conjunto de títulos por ele publicados $(88,0 \%)$. Assim, no caso francês, percebe-se que o gênero da publicação - bibliografia comentada - interfere fortemente na produtividade dos critérios relativos às informaçóes bibliográficas, que são os mais empregados, como, aliás, seria de se esperar em obras cujo objetivo era recomendar a compra de livros para composição de bibliotecas ou gabinetes de leitura. Excetuando-se essas informaçóes, praticamente obrigatórias, o critério mais empregado é também o comentário sobre o enredo.

Assim, quando se tratava de pensar sobre romances, os homens de letras do início do século XIX pensavam, sobretudo, nas tramas das narrativas e 
dedicavam a elas grande espaço em seus comentários. Sabendo que as críticas eram, em geral, curtas (ver Tabela 1), é impressionante ver que os comentários sobre enredo ocupam, em média 76,3 palavras no caso inglês, 52,3 no caso português e 17,5 no caso francês.

O enredo não apenas é o elemento mais destacado pelos críticos; ele é também aquele que produz maior quantidade de comentários negativos. No caso da censura, $67,8 \%$ das avaliaçóes de enredo são negativas, enquanto $59,6 \%$ das avaliaçóes publicadas nos periódicos britânicos o são. A taxa de reprovação nas bibliografias francesas é bem menor $(27,8 \%)$, o que é bastante compreensível, tendo em vista que, nessas obras, predomina a recomendação de romances tidos como bons.

A avaliação do enredo muitas vezes associava-se às consideraçóes sobre a moralidade do tema e de sua articulação na narrativa. Entre os portugueses, a moral foi empregada em 34 críticas $(68,0 \%)$, o que era de se esperar, tendo em vista que uma das obrigaçóes dos censores era justamente examinar a moralidade da obra. Mesmo tratando-se de dever de ofício, 32,0\% dos textos críticos deixou de comentar esse elemento, mostrando que a avaliação dos censores podia passar ao largo das determinaçóes régias, examinando elementos não previstos - como o enredo - e deixando de lado questóes centrais, como a moralidade.

Não se pense, entretanto, que a consideração da moral era uma preocupação exclusiva dos organismos de censura: este elemento está também presente em 21 textos críticos ingleses (42,0\%) e em 13 franceses (26,0\%). Muitos imaginariam que os censores abordariam a questão moral dos romances para recriminá-la, mas os dados apontam em outra direção: 84,3\% dos comentários sobre moral inseridos em textos de censura têm uma conotação positiva, ou seja, os censores exaltavam o bom tratamento moral presente nos romances que passavam por suas máos. Esta percentagem é muito mais alta do que a observada nas bibliografias francesas e nos periódicos ingleses, em que, no primeiro caso, os comentários morais são positivos em $64,7 \%$ das ocorrências, e no segundo em $59,1 \%$ das vezes.

A preocupação moral tem impacto sobre outro elemento muito produtivo nos comentários críticos: o efeito provocado pela leitura. Ele foi utilizado em 31 textos ingleses (62,0\%), 25 portugueses (50,0\%) e 15 franceses $(30,0 \%)$. Curiosamente, não são os textos de censura os mais preocupados com as repercussóes da leitura sobre a vida dos leitores. Os mais atentos a isso são os autores de críticas para periódicos britânicos. Entretanto, eles o fazem com atenção a aspectos distintos. Enquanto nos pareceres de censura os efeitos da leitura sobre a conduta e o comportamento dos leitores são o elemento de maior destaque, seguido de comentários sobre o possível entretenimento advindo da leitura, para os britânicos o foco é invertido, fazendo com que o 
entretenimento apareça em primeiro lugar e o impacto sobre o comportamento do leitor em segundo. Apesar desta pequena diferença, eles, em geral, achavam que os efeitos sobre os leitores seriam positivos: $53,7 \%$ das críticas publicadas em periódicos, $61,5 \%$ dos pareceres de censura e $84,2 \%$ dos comentários inseridos em bibliografias tiveram uma conotação positiva, matizando a ideia de que os letrados tinham uma prevenção contra o gênero em função de seu impacto sobre leitores (BARTOLOMEO, 1994).

Além de discutir o enredo e a moralidade das narrativas, os críticos ocupavam-se com a linguagem empregada nos romances: 29 textos em inglês $(58,0 \%), 21$ em português (42,0\%), 12 em francês $(24,0 \%)$ tecem consideraçóes sobre a qualidade da escrita, seja do ponto de vista estilístico, seja de sua correção. Há uma particular atenção à linguagem no caso das traduçóes, já que, em geral, o que se examinava nesses casos era a qualidade da linguagem do texto de chegada, muito mais do que a fidelidade ao romance original. Assim, a qualidade da tradução é comentada em 50,0\% dos pareceres de censura, $24,0 \%$ dos textos das bibliografias e $6,0 \%$ das críticas em periódicos. É fácil compreender a disparidade nesses números, tendo em vista a dessemelhança na produção nacional de ficção - enquanto Inglaterra e França contam com poucas traduçóes, em Portugal a maior parte dos romances saídos à luz é tradução de obra francesa e, em menor quantidade, inglesa. Novamente, é curioso observar que os censores tivessem preocupaçóes dessa natureza, entretanto eles acreditavam que a publicação de um texto com erros seria uma afronta à imagem da nação portuguesa e, portanto, anotavam zelosamente todos os desvios que encontravam, tanto do ponto de vista dos vocábulos quanto da construção sintática. De seu ponto de vista, a maior parte dos trabalhos continha problemas, elevando a $61,0 \%$ a porcentagem de comentários negativos quanto à qualidade da tradução submetida ao seu exame.

Da mesma forma, os censores extrapolavam suas obrigaçóes ao examinar a constituição das personagens e a verossimilhança da narrativa, chegando a exceder o que se fazia nas bibliografias francesas. Enquanto estas comentaram as personagens em apenas 10,0\% dos casos e a verossimilhança em 8,0\% das vezes, os censores trataram destes elementos em $18,0 \%$ e 16,0\% dos pareceres, respectivamente. Os ingleses eram mais preocupados com a constituição das personagens, abordada em $54,0 \%$ dos textos, e com a verossimilhança, comentada em 40,0\% dos textos críticos.

Percebe-se, assim, que há uma homogeneidade na seleção dos elementos empregados no comentário de obras ficcionais, embora a intensidade de sua utilização possa variar. 
Este experimento permitiu perceber como os homens de letras reagiam aos romances no início do século XIX. Ao contrário do que se poderia supor, não houve diferença importante na seleção dos critérios de análise que se concentraram sobre um mesmo e reduzido número de elementos textuais nos diferentes lugares. Assim, a língua em que os textos críticos foram escritos e sua finalidade não parecem ter sido um fator decisivo na definição do modo de compreender e comentar obras ficcionais.

Ainda assim, é possível observar algumas pequenas diferenças. A mais evidente delas parece ser o humor, elemento ignorado pelos críticos portugueses e franceses, mas com alguma presença entre ingleses, confirmando interpretaçóes já conhecidas sobre a importância do humor na cultura britânica (NILSEN, 1998). Da mesma forma, os britânicos foram os únicos a mencionar - ainda que muito parcimoniosamente - as descriçóes em seus comentários, o que talvez se explique pelo fato de os romances ingleses serem mais descritivos, o que era percebido muitas vezes com desagrado, por leitores e críticos de outros países (VASCONCELOS, 2016, p. 135-158). Os britânicos também revelaram alguma preocupação com a originalidade dos textos, elemento menos observado pelos demais críticos. Isto talvez se deva ao fato de eles serem aqueles que examinavam maior quantidade de obras, tendo em vista o alto volume de livros em circulação no Reino Unido, e de o fazerem para comentar os lançamentos na imprensa, o que provavelmente os tornava mais propensos a destacar a novidade de um texto quando a encontravam, ou a reclamar das repetiçóes de cenas e situaçôes já muito vistas.

A finalidade com que se produziram os comentários teve interferência em outros elementos. Os comentários publicados em bibliografias francesas e em periódicos britânicos trazem informações bibliográficas com frequência muito superior aos pareceres de censura, o que parece natural, já que ambos visavam orientar um possível comprador. No caso das bibliografias, cujo propósito era recomendar livros que ficassem bem em uma biblioteca ou que pudessem ser adquiridos por um homem de gosto sem receio, os comentários apresentaram um grau de positividade superior aos demais na maior parte dos elementos. Entretanto, os pareceres de censura, curiosamente, revelaram um índice de positividade mais alto do que os textos franceses e ingleses no julgamento da moral, e superior às críticas de periódicos como avaliação geral da obra.

Apesar de os críticos empregarem praticamente os mesmos critérios de análise, foi possível perceber que as publicaçôes em periódico recorreram a uma gama de elementos um pouco mais vasta. Ainda que não o fizessem com muita frequência, consideraram a originalidade / novidade do romance, 
a presença do humor, a qualidade das descriçóes e dos diálogos - elementos que passam despercebidos em bibliografias e pareceres de censura. Além disso, observaram com mais frequência a linguagem, as personagens e a verossimilhança das narrativas, fazendo com que seus textos críticos fossem mais detalhados e mais diversos em seus comentários. Talvez isso se deva ao fato de as críticas publicadas em periódicos serem uma atividade mais sistemática, mais volumosa e mais profissionalizada do que a elaboração de bibliografias e pareceres de censura.

Mesmo assim, o que predomina é a semelhança no modo de compreender e julgar a ficção disponível no período, mesmo quando se trata da censura lusitana, em que a inserção letrada dos avaliadores parece prevalecer sobre o papel de censor, fazendo que elementos não previstos nos alvarás régios rendam mais comentários do que o obrigatório exame da retidão política, religiosa e moral dos textos. Náo é à toa, portanto, que crítica e censura pudessem ser termos intercambiáveis naquela época, como se vê na edição de 1810 da Nouvelle Bibliothèque d'un Homme de Goût, na qual os homens que analisam livros na imprensa são designados como "censores", valorizando o fato de se ter recorrido apenas à avaliação de "censeurs judicieux" [censores judiciosos] na elaboração desta bibliografia (ANÔNIMO, 1808, p. I).

A diversidade de finalidades e propósitos tornou ainda mais interessante a comparaçáo, pois permitiu perceber que havia uma cultura comum aos homens de letras, que os fazia reagir aos romances de maneira semelhante, independentemente da língua em que escreviam e do propósito de suas análises.

\section{Referências bibliográficas}

ABREU, Márcia. Os Caminhos dos livros. Campinas: Mercado de Letras/ALB/ FAPESP, 2003.

ABREU, Márcia. Nos primórdios da crítica - julgamentos literários produzidos pela censura luso-brasileira. In: FIGUEIREDO, Carmen Lúcia N. de; HOLANDA, Sílvio Augusto de O.; AUGUSTI, Valéria (org.). Critica e literatura. Rio de Janeiro: De Letras, 2011, p. 197-220.

ANÔNIMO. Nouvelle Bibliothèque d'un Homme de Gout, ou Tableau de la Littérature ancienne et moderne, dans lequel on fait connoître l'esprit de tous les livres qui ont paru dans tous les genres jusqu'en 1797; avec un jugement sommaire et impartial sur chaque ouvrage, et l'indication des différentes édtions qui en on été faites, tant en France qu'en pays étranger. Troisième édition, corrigée et augmentée. Par une Société de Gens de Lettres. Paris: Ches Des Essarts, libraire, rue du Théâtre François, no. 9. L’An VI - 1798. Disponível em <https://archive.org/details/ nouvellebibliot01chaugoog> Acesso em 6 de março de 2017. 
ANÔNIMO. Nouvelle Bibliothèque d'un Homme de Gout, ou Tableau de la Littérature ancienne $\&$ moderne, étrangere $\&$ nationale, dans lequel on expose le sujet, \& l'on fait connoître l'esprit de tous les Livres qui ont paru dans tous les siecles, sur tous les genres, \& dans toutes les Langues, avec un jugement court, précis, clair \& impartial, tiré des Journalistes les plus connus, \& des Critiques les plus estimés de notre temps. Paris: Rue Saint Jacques, au Grand Corneille, 1777. Disponível em <https://archive.org/details/nouvellebibliot00chaugoog> Acesso em 21 de março de 2017.

BARTOLOMEO, Joseph F. A new species of criticism - eighteenth-century discourse on the novel. Newark/London and Toronto, University of Delaware Press/Associated University Press, 1994.

MITTMANN, A.; WILLRICH, R.; FILETO, R.; DOS SANTOS, A. L.; ASSIS, E. C. P.; SANDOVAL, I. M. B. DLNotes2: Anotaçôes Digitais como Apoio ao Ensino. XXIV Simpósio Brasileiro de Informática na Educação, 2013, p. 527-536.

MULLER, J.G.C. Memoria sobre a Litteratura Portugueza, traduzida do inglez com notas illustradoras do texto, por J. G. C. M. S/l, 1809.

NILSEN, Don Lee Fred. Humor in Eighteenth-and Nineteenth-Century British Literature: A Reference Guide. Westport: Greenwood, 1998.

OLIVEIRA, Francisco Xavier de. Elogio do Rey D. João 5. Manuscrito, 90 pág, s/d. Biblioteca Nacional de Lisboa - Sessão de Reservados - cota: COD 782.

OLIVEIRA, Francisco Xavier de. Elogios do Condestable D. Nuno Alvares Pereira, e Affonso de Albuquerque. Lisboa, na Offic. de João Antonio da Silva 1798. $8 .^{\circ}$ de $228 \mathrm{p}$.

OLIVEIRA, Francisco Xavier de. Panegyrico do Ill. ${ }^{\text {mo }}$ e Ex. ${ }^{\text {mo }}$ Sr. Sebastião José de Carvalho e Mello, primeiro Marquez de Pombal, Ministro e Secretario d'Estado de S. M. F. o Senhor D. José I. Escripto em 1772. Lisboa, na Imp. Regia 1815.

PIGOREAU, Alexandre-Nicolas. Petite Bibliographie biographico-romancière, ou Dictionnaire des romanciers, tant anciens que modernes, tant nationaux qu'étrangers; Avec un mot sur chacun d'eux, et la Notice des Romans qu'ils ont donnés, soit comme auteurs, soit comme traducteurs; précédé d'un catalogue des meilleurs romans, publiés depuis plusieurs années, et suivi de tableaux propres a en faire connaitre les différens genres, et a diriger dans le choix des ouvrages qui doivent faire la base d'un cabinet de lecture. Paris: Pigoreau, Libraire, Octobre, 1821. Disponível em <http://gallica.bnf.fr/ark:/12148/bpt6k108408n>. Acesso em 8 de março de 2017.

VASCONCELOS, Sandra Guardini. Circuitos e travessias: o caso de A Família Elliot. In: ABREU, Márcia (org.) Romances em movimento: a circulação transatlântica dos impressos (1789-1914). Campinas: Editora da Unicamp/FAPESP, 2016, p. $135-158$. 
Márcia Abreu. É professora do Departamento de Teoria Literária do IEL - UNICAMP. Publicou vários trabalhos, dentre as quais se destacam os livros The Transatlantic Circulation of Novels Between Europe and Brazil, 1789-1914 (Palgrave MacMillan, 2017); Romances em movimento (Editora da Unicamp, 2016); The Cultural Revolution of the Nineteenth Century: Theatre, the Book-Trade and Reading in the Transatlantic World (Org. com Ana Claudia Suriani da Silva. I.B. Tauris, 2015); Impresso no Brasil - dois séculos de livros brasileiros (org. com Aníbal Bragança. Editora da Unesp/Fundação Biblioteca Nacional, 2010), com o qual ganhou o Prêmio Jabuti 2011; Cultura Letrada: literatura e leitura (UNESP, 2006); Os Caminhos dos livros (Mercado de Letras/ALB/ FAPESP, 2003) e Histórias de Cordéis e Folhetos (Mercado de Letras/ALB, 1999). E-mail: marcia.a.abreu@gmail.com

Adiel Mittmann. Possui mestrado e doutorado em Ciências da Computação pela Universidade Federal de Santa Catarina (2016). Atua principalmente nos seguintes temas: Humanidades Digitais, Versificação, Linguística Computacional.

E-mail: adiel@mittmann.net.br 